\title{
Age Correction in Apatite Samples: influences of chemical composition and thermal history
}

Diego Scolfaro da Silva (IC), Sandro Guedes de Oliveira (PQ), Cleber José Soares (PG).

\section{Abstract}

The age provided by the Fission Track method may differ from the actual age due to temperature conditions to which the sample was subjected since its formation so correction methods can be applied based on analyzes made in the sample. The objective of this study is to establish relationships between the chemical composition and thermal history with the need to apply a correction method. So far our results point to confirm the hypothesis that chemical composition has influences on the thermal history experienced by the sample cause reduction in age.

Key words: Apatite, Fission Track, Chemical Composition

\section{Introduction}

Fission-Track Thermochronology is one of the radiometric dating tools.

The ${ }^{238} \mathrm{U}$, is present in nature as a impurity in the composition of most minerals. Its natural decay by spontaneous fission leaves a trail of damage to the structure of the material (the so-called Latent Track), which after a certain treatment may be observed and analyzed in order to infer the age of the material.

Since its formation, the mineral is subject to variable temperature and pressure, which can lead to reductions and even the deletion of the formed features. This phenomenon is known as annealing. Thus the age provided may differ from the correct one, so correction methods must be applied in order to obtain the correct age.

Previous works of the group show that samples with low degree of annealing ( 10\%) did not need correction at age obtained while samples with greater degree of annealing (between 15\% and $30 \%$ ) needed correction.

This work is inserted in this context, where we intend to get a justification for the fact that some samples require correction while others do not.

\section{Results and Discussion}

One proposed investigation is the analysis of the chemical composition of different samples, for the purpose of comparing samples having different degrees of age correction.

To date, the chemical composition of the samples was obtained by two different tools (ICPMS and Dissolution) and its results are being compared with correction curves for each sample.

Parallel analyzes of chemical compositions indicate high amounts of rare earth elements in the samples. One element is the Gadolinium, whose isotope ${ }^{157} \mathrm{Gd}$ has a high cross section for capture of thermal neutrons, which are used in the dating process. Thus, there may be some influence of the presence isotope from about the age provided. A sample of low degree of annealing and low correction in age (about 13\% and 3\%, respectively) was compared with one with a higher degree of annealing and large correction in age (about 20\% and 34\%, respectively). The chemical compositions, indicate a much greater amount of rare earths (in particular $\mathrm{Nd}$, which has an isotope with a cross section close to that of ${ }^{235} \mathrm{U}$ to capture thermal neutrons) into the sample that did not need correction.

\section{Conclusions}

So far the results encourage the hypothesis that motivates the work of the thermal history and the chemistry has great influence on the need to correct the age provided by Fission Track Method. The latest measures are being carried at the moment and will be reported, along with the final conclusions in the final report and internal congress.

\section{Acknowledgement}

I thank the SAE UNICAMP for financial support.

\footnotetext{
${ }^{1}$ Tello et al."Thermochronology of the South American platform in the state of São Paulo, Brazil,through apatite fission tracks."Rad. Meas.. 2005, 36, 635-340.

${ }^{2}$ SOARES,C.J. "Geocronologia por traço de fissão em apatitas de rochas alcalinas: comparação dos diferentes métodos de datação e calibração da dosimetria de nêutrons." (111 páginas).Tese Universidade Estadual Paulista. Rio Claro (SP), 13 de março de 2012.
} 